\title{
INMOVILIZACIÓN DE BACTERIAS POTENCIALMENTE DEGRADADORAS DE PETRÓLEO CRUDO EN MATRICES ORGÁNICAS NATURALES Y SINTÉTICAS
}

\author{
María Andrea REYES-REYES ${ }^{1}$, Edinson Andrés PUENTES-CALA ${ }^{1,2}$, \\ Eder Leonardo CASANOVA-MONTES ${ }^{1}$, Freddy LÓPEZ-DELUQUE ${ }^{1}$, \\ Jorge Hernando PANQUEVA-ÁLVAREZ ${ }^{1}$ y Genis Andrés CASTILLO-VILLAMIZAR ${ }^{1,3 *}$
}

${ }^{1}$ Corporación para la Investigación de la Corrosión, km 2, Via Refugio, Sede UIS Guatiguará, Piedecuesta,
Santander, Colombia 681011
2 Max Planck Institute for Marine Microbiology, Celsiusstr 1, D-28359, Bremen, Alemania
${ }^{3}$ Department of Genomic and Applied Microbiology, Institute of Microbiology and Genetics,
Georg August University Göttingen, Grisebachstr 8, D-37077 Göttingen, Alemania
*Autor para correspondencia: gcastil@gwdg.de

(Recibido febrero 2016, aceptado marzo 2018)

Palabras clave: alginato de sodio, biomasa inmovilizada, consorcio bacteriano, biorremediación, poliuretano

\section{RESUMEN}

En este estudio se conformó un consorcio de bacterias potencialmente degradadores de petróleo aisladas de lodos aceitosos provenientes de un campo petrolero del nororiente colombiano. El consorcio está compuesto por cinco cepas degradadoras de crudo de rápido crecimiento, pertenecientes a los géneros Bacillus sp., Pseudomonas sp., Serratia sp., Raoultella sp. y Enterobacter sp. Con el fin de potenciar la versatilidad del consorcio bacteriano, se evaluaron diversos tipos de matrices sólidas para su inmovilización, las cuales incluyeron matrices orgánicas de origen natural (encapsulación por goteo de alginato de sodio) y sintético (adhesión en once matrices diferentes de poliuretano). La biomasa inmovilizada se cuantificó mediante recuento por microgota y peso seco. Adicionalmente, se analizó cualitativamente la distribución de los microorganismos en superficies e intersticios mediante microscopia electrónica de barrido. En todos los casos se observó algún grado de inmovilización de biomasa; sin embargo, los resultados indican que la encapsulación con alginato de sodio al 3 $\%$ y la inmovilización en las espumas de poliuretano PUF\#10 y PUF\#37 son más eficientes en términos de cantidad de biomasa bacteriana inmovilizada. Teniendo en cuenta su condición de biodegradables, las matrices de alginato de sodio y espuma PUF\#10 se perfilan como las mejores opciones para este consorcio particular en futuros tratamientos de biorremediación.

Key words: bacterial consortium, immobilized biomass, sodium alginate, bioremediation, polyurethane

\begin{abstract}
In this study a bacterial consortium was assembled using isolates from an oily sludge sampled at a northeastern Colombian oil field. The consortium contains five putative oil degrading fast-growing strains associated to the genera Bacillus sp., Pseudomonas sp., Serratia sp., Raoultella sp. and Enterobacter sp.. In order to enhance its versatility the
\end{abstract}


immobilization of the bacterial mixture was tested using several solid supports, which included matrices of natural (sodium alginate) and synthetic (polyurethane) origin. The immobilized biomass was analyzed by microdroplet counting, dry weight and electron microscopy. Although bacterial immobilization was observed in all cases, $3 \%$ sodium alginate, PUF\#10 and PUF\#37 matrices showed the highest amount of biomass retention. Additionally, the environmentally relevant feature of biodegradability reported for sodium alginate and PUF\#10 matrices favors their further testing and eventual use for bioremediation treatments, using the hereby evaluated consortia.

\section{INTRODUCCIÓN}

El petróleo crudo es una mezcla heterogénea de sustancias hidrocarbonadas de alta toxicidad ambiental. Estas propiedades hacen de la biodegradación del crudo y sus derivados un proceso lento y en su mayor parte incompleto (Emtiazi et al. 2005, Arrieta 2011). La demanda energética actual es dependiente de combustibles fósiles, situación que ha llevado al incremento de las actividades de exploración, producción, transporte y almacenamiento de hidrocarburos. Pese a los estándares de seguridad que rigen la industria, los vertimientos, en su mayoría accidentales, generan desequilibrio en los ecosistemas e impactan negativamente el aprovechamiento de otros recursos naturales (Núñez et al. 2010, Ferreira et al. 2013).

A nivel global, los vertimientos de hidrocarburos son frecuentes y de diversos orígenes. Se calcula que el $10 \%$ de la contaminación total por hidrocarburos en los océanos está relacionado con naufragios de naves de carga y explotación petrolera. Un porcentaje importante de la contaminación por crudo proviene de aguas continentales contaminadas con hidrocarburos: ríos, manglares y escorrentías urbanas (Lozano 2005, Olguín et al. 2007). En Colombia, una alta proporción de derrames de hidrocarburos han sido ocasionados por atentados terroristas a la infraestructura de transporte y en menor medida por accidentes industriales. Aunque el número de derrames en el territorio colombiano ha disminuido durante la última década, la baja biodegradabilidad del petróleo continúa afectando numerosos ecosistemas, lo cual incide negativamente en la estabilidad y productividad del país (Lozano 2005).

Para restaurar ambientes contaminados con crudo se han utilizado diversas estrategias, las cuales se seleccionan de acuerdo con las características y condiciones del área contaminada. El uso de microorganismos, plantas y enzimas como catalizadores para la degradación de hidrocarburos se ha perfilado como una alternativa cada vez más utilizada en la industria petrolera (Vargas et al. 2004, Olguín et al. 2007, Núñez et al. 2010, Martínez et al. 2011). Una de las estrategias de biorremediación más empleada es la atenuación natural, la cual depende completamente de procesos naturales para la degradación de los contaminantes. Sin embargo, dado su carácter pasivo, esta técnica requiere tiempos largos para su aplicación (Olguín et al. 2007, Arrieta 2011, Martínez et al. 2011). Una variante de la atenuación natural es la bioestimulación, que consiste en promover la proliferación de microorganismos nativos del medio contaminado mediante la adición de nutrientes (Vargas et al. 2004).

Otra estrategia de amplia utilización en procesos de biorremediación es la denominada bioaumentación, que se fundamenta en la inoculación de una alta concentración de microorganismos o enzimas en el área contaminada (Olguín et al. 2007, Martínez et al. 2011). Con esta técnica, los microorganismos son aislados, seleccionados y cultivados directamente del sitio contaminado. Algunas variaciones de este método han incluido recientemente el uso de microorganismos modificados genéticamente (Arrieta 2011).

Los numerosos procesos de biorremediación por bioaumentación pueden aplicarse utilizando bacterias tanto aerobias como anaerobias. Sin embargo, la mayoría de las investigaciones reportadas se centran en las bacterias de tipo aerobio (Xu y Lu 2010, Vennila y Kannan 2011, Lakshmi 2013). Algunos de los factores limitantes en el uso microorganismos libres son, entre otros, la falta de control sobre el crecimiento bacteriano luego de su aplicación, la pérdida significativa de biomasa, la susceptibilidad a los cambios de temperatura, $\mathrm{pH}$, humedad y oxigenación. Otra desventaja importante del uso de bacterias libres es la exposición de los microrganismos a un ambiente relativamente hostil. En este sentido, el número y la eficiencia de los microorganismos viables con capacidad degradadora de hidrocarburos son afectados cuando contaminantes tóxicos están presentes en altas concentraciones o por competencia directa con 
otros microorganismos nativos (López et al. 2006, Xu y Lu 2010, Malik y Ahmed 2012).

Con el objeto de minimizar el impacto de estos factores se ha impulsado el uso de nuevas tecnologías, como la inmovilización de biomasa activa (Rahman et al. 2006, Garzón y Barragán 2008, Monge et al. 2008, Bayat et al. 2015). El uso de matrices de inmovilización tiene ventajas, entre las que resaltan el aumento de la estabilidad catalítica y de la actividad metabólica. Asimismo, la inmovilización permite el incremento de la viabilidad de las células inmovilizadas en comparación con las técnicas que usan células libres. Los factores determinantes en el mejoramiento de estas condiciones son el aumento de biomasa en el soporte, la concentración de nutrientes alrededor de la matriz, la mayor estabilidad de las células y, en consecuencia, la protección contra condiciones externas adversas (Rahman et al. 2006, Wang et al. 2015).

Los microorganismos pueden ser inmovilizados de forma reversible o irreversible. La inmovilización reversible se lleva a cabo induciendo la adhesión de las células a superficies de matrices naturales o sintéticas como la zeolita, el poliuretano (PU), el alcohol de polivinilo (PVA), la poliacrilamida y el polietilenglicol, entre otros (Quek et al. 2006, Monge et al. 2008, Usha et al. 2010, Silveira et al. 2013, Wang et al. 2015).

Por otra parte, la estrategia de inmovilización irreversible presenta diversas alternativas. Sin embargo, uno de los métodos irreversibles más estudiados es la encapsulación de células al interior de esferas gelatinosas (Yamaguchi et al. 1999, Verbelen et al. 2006, Silveira et al. 2013). Este tipo de inmovilización protege al biocatalizador de condiciones ambientales adversas, pero la velocidad de reacción queda limitada a la difusión de los sustratos a través de la matriz inmovilizadora. Algunas de las matrices más utilizadas en esta metodología son el alginato, agar, sílica, carragenina y gelatina, entre otros (Manohar y Karegoudar 1998, Moslemy et al. 2002, Rahman et al. 2006, Young et al. 2006, Usha et al. 2010).

El alginato es el polímero de origen orgánico más utilizado para procesos de inmovilización, debido a que es de fácil manejo, posee baja o nula toxicidad, es de alta disponibilidad y bajo costo. Asimismo, ofrece una gran ventaja a las células inmovilizadas, dado que éstas no requieren cambios fisicoquímicos extremos durante los procesos de inmovilización (Silveira et al. 2013). Otros tipos de matrices e inmovilizadores con bases de poliuretano se han analizado con relativo éxito, incluso a nivel industrial (Wang et al. 2015). Este trabajo analiza y compara las tasas de inmovilización de un consorcio bacteriano con potencial para la degradación de hidrocarburos por encapsulación de células utilizando alginato de sodio, y por adhesión mediante el empleo de diferentes tipos de matrices de poliuretano.

\section{MATERIALES Y MÉTODOS}

\section{Conformación del consorcio bacteriano}

La recolección de muestras se llevó a cabo en lodos contaminados con petróleo crudo provenientes de un campo petrolero ubicado en la región centro-oriental de Colombia. La muestra general estaba compuesta por diez submuestras obtenidas de manera aleatoria. Todas las submuestras fueron transferidas a frascos de vidrio estéril y transportadas en refrigeración a $4{ }^{\circ} \mathrm{C}$ hasta el laboratorio. Se aplicó la metodología convencional para la preparación de diluciones seriadas del suelo (Madigan et al. 1999). Con el objeto de recuperar el mayor número de cepas se realizó una siembra inicial en el medio Luria-Bertani (LB) sólido con un $\mathrm{pH}$ de 7. Un total de 29 cepas bacterianas fueron aisladas por agotamiento en este mismo medio. Cantidades equivalentes de cada cepa se mezclaron e inocularon en el medio basal de sales (MBS) enriquecido con $\mathrm{NaCl} 0.3 \mathrm{~g} / \mathrm{L}$, $\left(\mathrm{NH}_{4}\right)_{2} \mathrm{SO}_{4} 0.6 \mathrm{~g} / \mathrm{L}, \mathrm{K}_{2} \mathrm{HPO}_{4} 0.75 \mathrm{~g} / \mathrm{L}, \mathrm{KH}_{2} \mathrm{PO}_{4}$ $0.25 \mathrm{~g} / \mathrm{L}, \mathrm{MgSO}_{4} 0.15 \mathrm{~g} / \mathrm{L}, \mathrm{KNO}_{3} 0.6 \mathrm{~g} / \mathrm{L}$ y $0.1 \%$ de crudo pesado como única fuente de carbono, con $\mathrm{pH}$ de 7.1 (Emtiazi et al. 2005). El medio fue incubado a $27^{\circ} \mathrm{C}$ con agitación constante (150 rpm) durante un periodo de $72 \mathrm{~h}$. El cultivo fue diluido en solución salina hasta $10^{-8}$ y subsecuentemente sembrado por extensión en placa sobre medios LB y MBS sólidos según la metodología descrita por Dasgupta et al. (2013) con modificaciones. La conformación del consorcio bacteriano se realizó utilizando las cepas viables postcultivo, formadoras de estructuras micelares en MBS con hidrocarburo como única fuente de carbono según lo descrito por Pérez et al. (2008). Mediciones preliminares del potencial degradador del consorcio fueron realizadas por gravimetría de extracción con hexano utilizando el método estandarizado 5520B para medición de aceites y grasas de la Asociación Americana de Salud Pública (APHA/AWWA/ WEF 2012). Para este ensayo se usaron $100 \mathrm{~mL}$ de muestra, previamente acidificada con ácido clorhídrico en relación de volumen 1:1. Una vez alcanzado un $\mathrm{pH}$ de 2 o menor, la muestra fue sometida a separación por embudo, seguida de extracción líquidolíquido. La fase orgánica de la extracción se depuró con un filtro previamente impregnado con hexano y sulfato de sodio $\left(\mathrm{Na}_{2} \mathrm{SO}_{4}\right)$. Se adicionaron partículas 
de sílice para retirar las grasas no pertenecientes a los hidrocarburos totales de petróleo (HTP). Finalmente, se cuantificaron las concentraciones de HTP durante 15 días de cultivo en lote, mediante análisis de gravimetría.

Las bacterias seleccionadas como potencialmente degradadoras de hidrocarburos se identificaron mediante amplificación y posterior secuenciación del gen 16S ARNr. Las secuencias obtenidas se ensamblaron utilizando la herramienta GAP5 (Bonfield y Whitwham 2010). Las secuencias ensambladas se alinearon manualmente con la base de datos de SILVA (Quast et al. 2013), para su correspondiente asignación taxonómica.

\section{Inmovilización del consorcio bacteriano en cáp- sulas de alginato de sodio}

Concentraciones equivalentes de cada cepa potencialmente degradadora de hidrocarburos se mezclaron e inocularon en $1000 \mathrm{~mL}$ de medio de cultivo líquido: (diésel $1.6 \mathrm{~mL} / \mathrm{L}$, fertilizante para plantas con nitrógeno, fósforo y potasio [NPK] a $8 \mathrm{~mL} / \mathrm{L}$, extracto de levadura $0.1 \mathrm{~g} / \mathrm{L}$, aforado hasta $1000 \mathrm{~mL}$ con agua). Los cultivos se incubaron durante $48 \mathrm{~h}$ a $32{ }^{\circ} \mathrm{C}$, con agitación de $150 \mathrm{rpm}$. Todos los ensayos se realizaron por duplicado siguiendo las indicaciones descritas por Łebkowska et al. (2011) con leves modificaciones.

Se utilizaron soluciones al 2, 2.5, 3 y $4 \%$ de alginato de sodio preparadas en agua destilada a $70{ }^{\circ} \mathrm{C}$, homogenizadas y esterilizadas en autoclave por el método de calor húmedo $\left(120^{\circ} \mathrm{C}, 137.8 \mathrm{KPa}\right.$, 20 min). Cada solución de alginato se inoculó con células del consorcio bacteriano hasta alcanzar una concentración de $1 \times 10^{8} \mathrm{UFC} / \mathrm{mL}$. Después de su homogeneización, las suspensiones bacterianas fueron agregadas por goteo a una solución estéril $0.1 \mathrm{M}$ de cloruro de calcio $\left(\mathrm{CaCl}_{2}\right)$ a $4{ }^{\circ} \mathrm{C}$ con agitación a $50 \mathrm{rpm}$ (Sossa et al. 2008, Hoskeri et al. 2014), resultando en la encapsulación de la biomasa en la matriz de alginato. Las cápsulas se incubaron por $12 \mathrm{~h}$ a $4{ }^{\circ} \mathrm{C}$ en la solución de $\mathrm{CaCl}_{2}$ para su estabilización. Finalmente, las cápsulas se lavaron con agua destilada estéril para eliminar el exceso de iones de calcio antes de su uso (Sultana et al. 2000, Chitiva y Dussán 2003, Young et al. 2006).

Para determinar la cantidad de biomasa inmobilizada, se anadió $1 \mathrm{~g}$ de cápsulas de alginato de sodio a $9 \mathrm{~mL}$ de solución salina $(0.85 \%)$. La mezcla fue incubada en baño termostatado a $30{ }^{\circ} \mathrm{C}$ por $15 \mathrm{~min}$ y posteriormente se homogenizó con vórtex suave (Chitiva y Dussán 2003, Wang et al. 2009). El proceso se repitió hasta obtener la solubilización completa de las cápsulas. De la suspensión obtenida se realizaron diluciones seriadas en base diez, desde $10^{-1}$ hasta $10^{-8}$. Cada dilución fue procesada para el recuento de microorganismos por microgota. De forma simultánea se empleó un segundo método de solubilización celular por maceración; sin embargo, no se encontraron diferencias significativas en comparación con el método de vórtex (datos no mostrados).

\section{Inmovilización del consorcio bacteriano en ma- trices de poliuretano}

La selección de la mejor matriz de inmovilización de poliuretano (PU) se realizó mediante la evaluación de dos tipos de espumas. Por un lado, las denominadas espumas de poliuretano (PUF, por sus siglas en inglés), de tipo petroquímico y biodegradables, y, por otro lado, las resinas resinas de poliuretano sólidas (PUS). Las PUF de origen petroquímico se denominaron PUF\#1 y PUF\#37. Las biodegradables se designaron como PUF\#0, PUF\#10, PUF\#20, PUF\#21, PUF\#29 y PUF\#36. Estos números hacen referencia a la relación entre los polioles y el diisocianato en cada una de las espumas evaluadas. En este caso, se utilizaron PUF biodegradables con aceite de ricino. Por otra parte, el consorcio bacteriano se inmovilizó en tres PUS. En las denominadas PUS\#0 y PUS\#15, los números hacen referencia a la relación entre el glicerol y el diisocianato. La tercera PUS analizada es una resina sólida con fibra de vidrio en su interior denominada PUS + VIDRIO. En total se analizaron 11 matrices.

Las PUF y PUS se cortaron en cubos de aproximadamente $0.5 \mathrm{~cm}$ por lado y se lavaron tres veces con agua destilada estéril. Posteriormente las piezas se esterilizaron en autoclave (Ahuja y Souza 2009), se secaron a $80^{\circ} \mathrm{C}$ y se pesaron en una balanza analítica OHAUS PA 214 (Parsippany, NJ) (Wang et al. 2013).

El ensayo se realizó en Erlenmeyers de $250 \mathrm{~mL}$ con $100 \mathrm{~mL}$ de medio LB líquido, inoculado con un $10 \%$ de volumen del consorcio bacteriano cultivado en el medio descrito por Łebkowska et al. (2011) modificado y $1 \mathrm{~g}$ de matriz de poliuretano. Los Erlenmeyers se incubaron a $25^{\circ} \mathrm{C}$ con agitación constante $(150 \mathrm{rpm})$ durante $24 \mathrm{~h}$. Todos los ensayos se realizaron por duplicado (Gómez et al. 2008).

Subsecuentemente, las matrices se retiraron del medio de cultivo y secadas a $80{ }^{\circ} \mathrm{C}$, por $4 \mathrm{~h}$. Finalmente, fueron transferidas a un desecador y pesadas repetidamente hasta alcanzar peso constante. La diferencia de peso de las matrices secas antes y después de su inmersión en el cultivo bacteriano fue utilizada para calcular el peso de la biomasa bacteriana inmovilizada por gramo de matriz de PU (Moreno y Ospina 2008). 
La biomasa inmovilizada en matrices de poliuretano fue analizada por microscopia electrónica de barrido ambiental (MEBA) con un equipo Quanta 650 FEG, con imágenes de alta resolución a alto vacío por detección de electrones secundarios (SE). Las matrices se sometieron a un proceso de recubrimiento con partículas de carbón, a fin de crear una diferencia de densidades electrónicas en las superficies analizadas (Hincapié y Ramírez 2009). Las imágenes se obtuvieron de cortes laterales y transversales de 4 a $500 \mu \mathrm{m}$. Adicionalmente, se realizó en MEBA un análisis elemental de la superficie de la biopelícula formada en la superficie de las matrices de poliuretano, mediante la sonda EDAX (serie SDD). Se identificaron los elementos presentes en la muestra y se evaluaron los porcentajes elementales en un punto específico en la superficie de la biomasa.

\section{Análisis estadístico \\ Todos los experimentos se realizaron por duplica- do y los datos obtenidos en la cuantificación de bio- masa inmovilizada se compararon mediante análisis de varianza de un factor $\mathrm{p} \leq 0.05$, con el programa Statgraphics Centurion XVI.I.}

\section{RESULTADOS}

\section{Conformación del consorcio bacteriano}

De las muestras de lodos contaminados con crudo, se aislaron en medios LB líquido y sólido, un total de 29 cepas bacterianas. La inspección microscópica de las cepas reveló un predominio de bacilos Gram positivos (12 cepas), seguido de bacilos Gram negativos (10 cepas), cocobacilos Gram negativos (seis cepas) y en menor cantidad cocos Gram positivos (una cepa) (Fig. 1).

Todas las cepas bacterianas aisladas se mezclaron en MBS con hidrocarburo. Durante el tiempo de incubación se evidenció cambio de coloración en el medio, acompañado de aumento de la turbidez y formación de estructuras micelares, típicas en procesos de degradación de hidrocarburos (Riojas et al. 2010).

De un total inicial de 29 cepas inoculadas, cinco (equivalentes al $17 \%$ ) fueron recuperadas al finalizar el ensayo. Todas las cepas viables al finalizar el ensayo con posterior siembra en medio MBS con hidrocarburo, se catalogaron como positivas en formación de estructuras micelares.

$\mathrm{El}$ análisis conjunto en medio líquido de las cinco cepas potencialmente degradadoras de hidrocarburos en estado libre, evidenció una reducción promedio del $33 \%$ de los HTP respecto a los valores iniciales

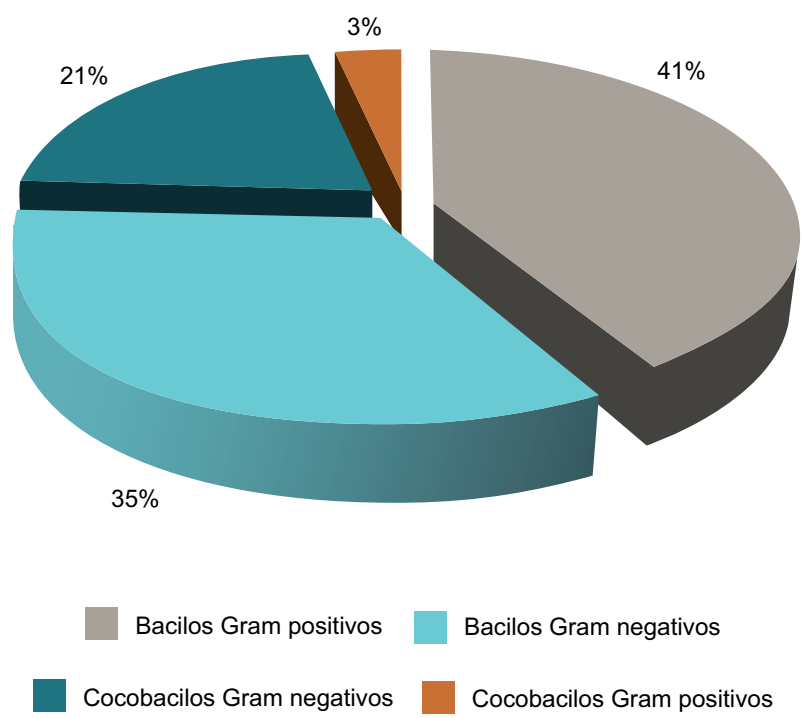

Fig. 1. Tipos de bacterias potencialmente degradadoras de hidrocarburos aisladas según morfología y tinción de Gram (bacilos Gram positivos, bacilos Gram negativos, cocobacilos Gram negativos, cocobacilos Gram positivos)

de todos los ensayos (Fig. 2). Luego del periodo de incubación, se realizaron análisis de morfología y secuenciación, revelando la presencia de todas las cepas iniciales del consorcio.

$\mathrm{El}$ análisis de las secuencias del gen $16 \mathrm{~S} \mathrm{ARNr}$ permitió la asignación taxonómica de las cepas seleccionadas hasta el nivel de género (identidad nucleotídica: > 95 \%) (Rosselló y Amann 2001). De esta manera, se logró establecer que el consorcio bacteriano está conformado por bacterias asociadas a los géneros Bacillus sp., Pseudomonas sp., Serratia sp., Enterobacter sp. y Raoultella sp. (Cuadro I).

\section{Inmovilización del consorcio bacteriano por en- capsulación, empleando alginato de sodio}

La inmovilización del consorcio bacteriano en cápsulas de alginato de sodio mostró resultados positivos en las cuatro concentraciones de alginato evaluadas. Se encontraron diferencias significativas en la forma de las cápsulas, pero no en su tamaño. Los resultados de la biomasa inmovilizada para cada concentración de alginato se presentan en la figura 3a. La comparación de biomasa inmovilizada en las diferentes concentraciones de alginato de sodio evidenció diferencias estadísticamente significativas ( $95 \%$ de confianza y $\mathrm{p} \leq 0.05$ ). La concentración de alginato de sodio al $3 \%$ inmovilizó la mayor cantidad de biomasa $\left(8.1 \times 10^{7} \mathrm{UFC} / \mathrm{g}\right.$ de cápsulas). En contraste, el ensayo con perlas de alginato de sodio al $4 \%$ mostró los valores más bajos de biomasa inmovilizada. 


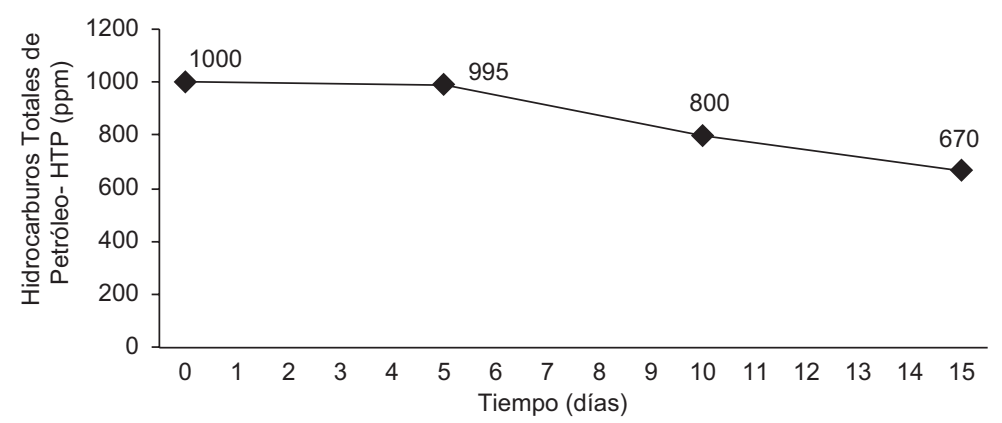

Fig. 2. Degradación de hidrocarburos totales de petróleo (HTP) por el consorcio bacteriano durante un periodo de incubación de 15 días

CUADRO I. IDENTIFICACIÓN MOLECULAR DE LAS CEPAS, INCLUYENDO VALORES DE SIMILITUD CON LOS GÉNEROS MÁS CERCANOS

\begin{tabular}{llc}
\hline Cepa & $\begin{array}{l}\text { Clasificación } \\
\text { taxonómica }\end{array}$ & $\begin{array}{c}\text { Porcentajes de similitud } \\
(\%)\end{array}$ \\
\hline Cepa 1 & Bacillus sp. & 100 \\
Cepa 2 & Pseudomonas sp. & 99 \\
Cepa 3 & Serratia sp. & 100 \\
Cepa 4 & Enterobacter sp. & 98 \\
Cepa 5 & Raoultella sp. & 99 \\
\hline
\end{tabular}

\section{Inmovilización del consorcio bacteriano en ma-} trices de poliuretano

A través de la comparación múltiple de las matrices de poliuretano se observó que entre las matrices sólidas (PUS\#0, PUS\#15 y PUS + VIDRIO) y la PUF\#21 no existen diferencias estadísticamente significativas, siendo éstas las matrices que menor biomasa inmovilizaron $(0.1 \mathrm{a} 39 \mathrm{mg} / \mathrm{g})$. Las matrices PUF\#37 y la PUF\#10 retuvieron 252.1 y $256.8 \mathrm{mg} / \mathrm{g}$ de biomasa, respectivamente (Fig. 3b). La caracterización física de estas últimas no mostró diferencias estadísticamente significativas $(p<0.05$, nivel de confianza $95 \%$ ).

La figura 4 muestra micrografías de las células inmovilizadas y biopelículas adheridas en las matrices de poliuretano analizadas mediante MEBA. En éstas se observan claramente las porosidades propias de las espumas de poliuretano (Fig. 4a-j). En la figura 41 se observan los bordes refringentes de la PUF\#37 de origen petroquímico, los cuales no fueron observados en las demás espumas biodegradables analizadas. En todas las matrices se observaron microorganismos adheridos; no obstante, desde un punto de vista cualitativo la alta densidad bacteriana presente en la PUF\#10 fue más evidente (Fig. 4d). Las matrices sólidas de poliuretano mostraron la formación de pequeñas biopelículas localizadas preferentemente en los bordes de las superficies de las matrices (Fig. 4k, m). La formación de estructuras morfológicamente similares a exopolímeros se resalta en la figura $4 \mathbf{n}$.

La composición elemental de la biopelícula formada en las PUF se determinó mediante espectrometría de dispersión de energía de rayos $\mathrm{X}$ (EDS), análisis que se aplicó a la PUF\#10 por ser ésta una de las matrices de poliuretano que más biomasa inmovilizó (Fig. 5). Se detectaron carbono (47.9\%), oxígeno $(21.2 \%)$, nitrógeno $(12.7 \%)$, sodio $(7.6 \%)$, fósforo $(0.4 \%)$, azufre $(0.5 \%)$, cloro $(8.5 \%)$ y potasio $(1 \%)$ (Fig. 5). Elementos como el hidrógeno están sin duda presentes en las muestras analizadas; sin embargo, las limitaciones de la técnica hacen que las señales de este elemento se traslapen con las de otros elementos presentes.

\section{DISCUSIÓN DE RESULTADOS}

La identificación de microorganismos nativos responsables de la biodegradación de contaminantes y su caracterización se han reportado como elementos necesarios para la evaluación, desarrollo y aplicación de estrategias de biorremediación in situ (Echeverri et al. 2010, Mrozik y Piotrowska 2010). Algunos miembros del dominio Bacteria tienen la capacidad de crecer, emulsificar y degradar hidrocarburos derivados del petróleo (Pérez et al. 2008). La biorremediación de ambientes contaminados utilizando bacterias biodegradadoras de hidrocarburos ha sido exitosa utilizando tanto microrganismos de una sola especie como consorcios bacterianos (Brune y Bayer 2012, Shankar et al. 2014).

Una de las ventajas de utilizar cultivos mixtos radica en la capacidad de degradar varios componentes del contaminante de forma simultánea y no de forma secuencial, como cuando se degradan usando cultivos puros (Barrios 2011). En este estudio se estableció un 

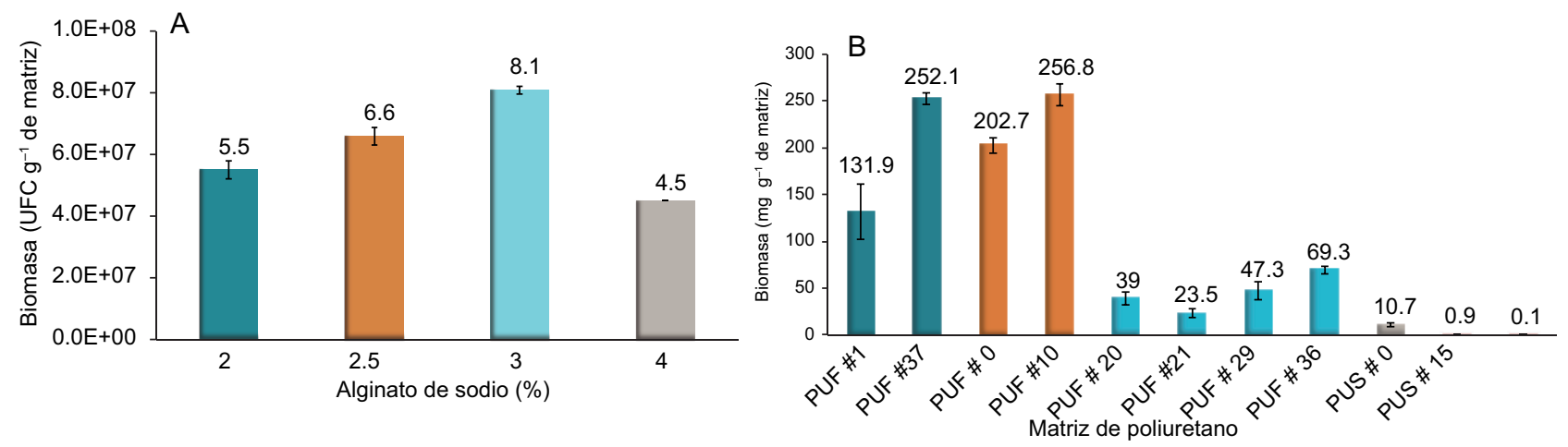

Fig. 3. Concentración de biomasa inmovilizada en matrices orgánicas natural (las barras de error corresponden a la desviación estándar de cada medición realizada por duplicado). (a) Biomasa inmovilizada en cápsulas de alginato de sodio. (b) Cantidad de biomasa inmovilizada en matrices de poliuretano. PUF: espumas de poliuretano, PUS: poliuretano sólido
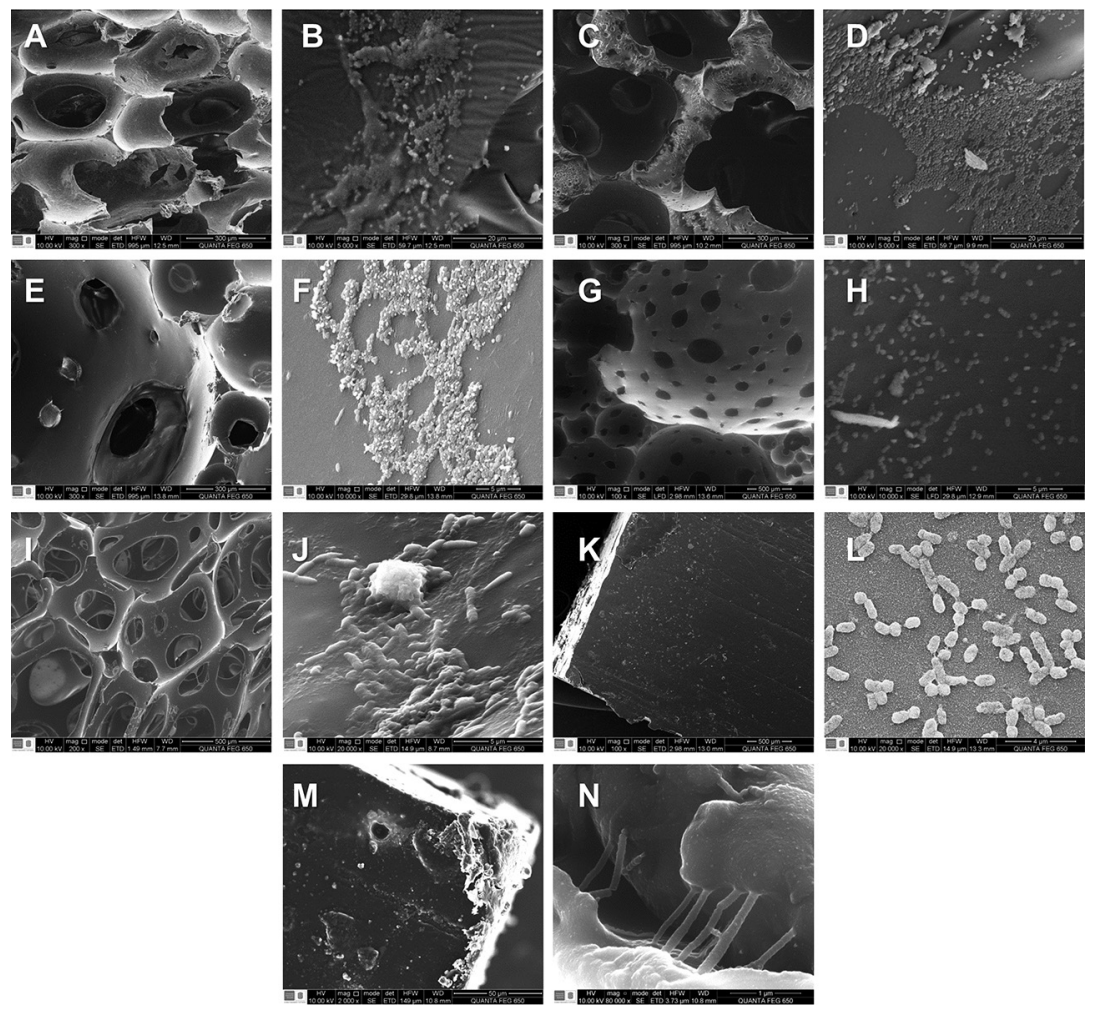

Fig. 4. Micrografías en microscopia electrónica de barrido ambiental en superficies de las matrices de poliuretano y la adhesión del consorcio bacteriano. (a) PUF\#0 $(\times 300)$. (b) PUF\#0 con biopelícula del consorcio bacteriano adherido en la superficie de uno de los poros $(\times 500)$. (c) PUF\#10 $(\times 300)$. (d) PUF\#10 con presencia de biopelícula $(\times 5000)$. (e) PUF\# $20(\times 300)$. (f) PUF\#20, presencia de biopelícula $(\times 1000)$. (g) PUF\#29 (× 100). (h) PUF\#29, formación de biopelícula en el borde de uno de los poros (× 10 000). (i) PUF \# $37(\times 200)$. (j) PUF\#37 biopelícula formada por bacterias en la superficie de uno de los poros ( $\times 20$ 000). (k) PUS\#0 (× 100). (1) PUS\#0, bacterias adheridas a la superficie y formación de polisacáridos $(\times 20000)$. (m) PUS\#15, se observa biopelícula en la esquina de la matriz $(\times 2000)$. (n) PUS\#15, se observa la formación de biopelícula $(\times 80000)$. PUF: espumas de poliuretano, PUS: poliuretano sólido 


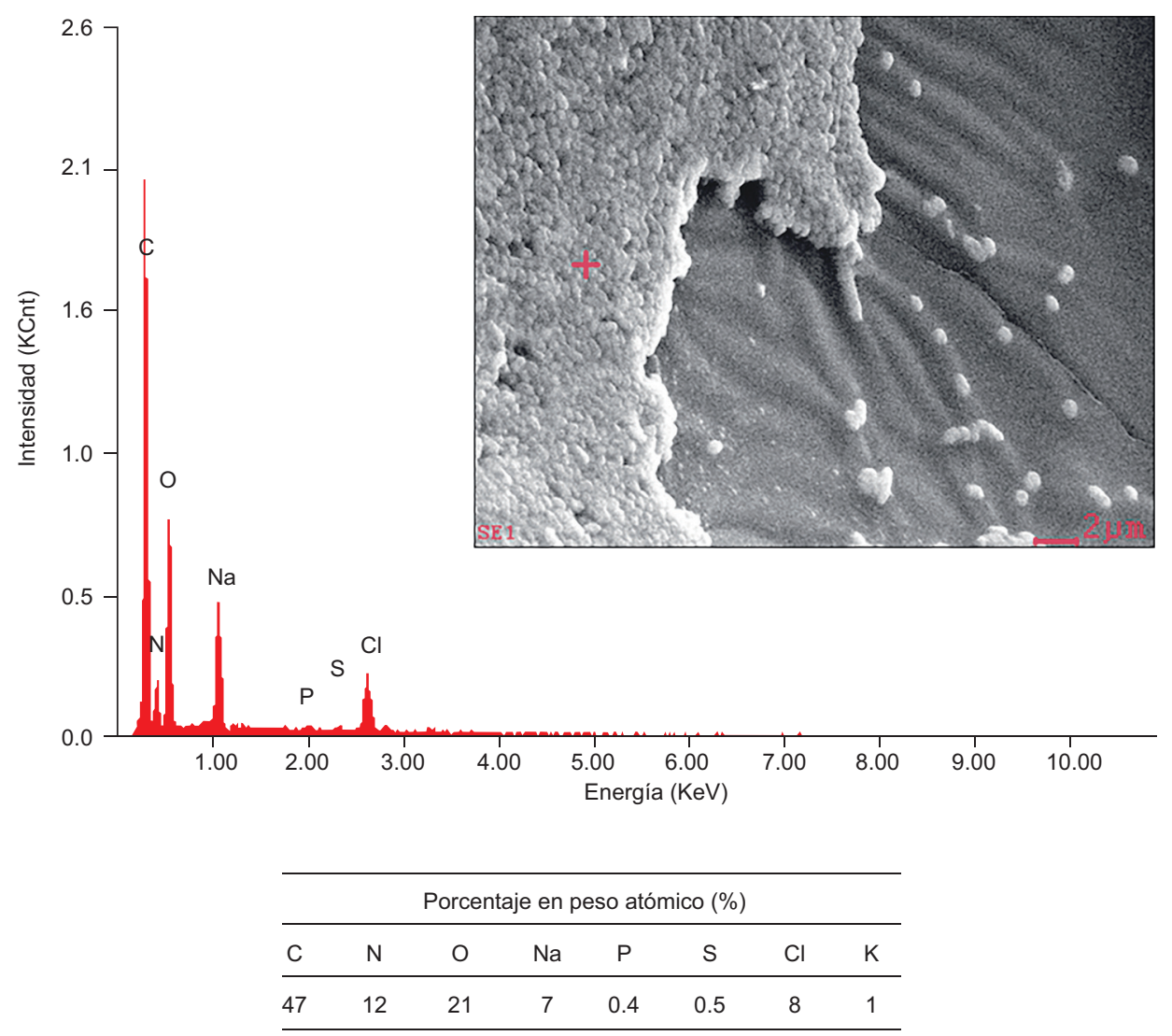

Fig. 5. Resultados del análisis elemental por espectrometría de dispersión de energía de rayos $X$ de la biopelícula formada en la espuma de poliuretano número 10 (PUF\#10)

consorcio bacteriano potencialmente biodegradador de hidrocarburos que en estado libre disminuyó en promedio $33 \%$ de los HTP iniciales del cultivo. De las cinco bacterias seleccionadas, una fue identificada como Gram positiva de tipo bacilo y cuatro como Gram negativas: tres bacilos y un cocobacilo. Las cinco cepas potencialmente degradadoras de hidrocarburos se recuperaron luego del cultivo en lote por 15 días. Este hecho evidencia que, en principio, ninguna cepa es totalmente inhibida por acción de las otras. No obstante, se carece de un análisis de tipo cuantitativo de la dinámica poblacional de las cepas utilizadas en el lote de cultivo para determinar o inferir de forma más clara sus interacciones.

Teniendo en cuenta las desventajas anteriormente mencionadas de la utilización de células libres en procesos de biodegradación, el objetivo principal de este trabajo estuvo enfocado a la inmovilización de biomasa bacteriana proveniente de cepas con potencial biodegradador de hidrocarburos. Durante la inmovilización del consorcio bacteriano en matrices de alginato de sodio, se observó que independientemente de la concentración del alginato, el inóculo inmovilizado no entra en contacto con el medio exterior y la matriz actúa como una barrera de protección. Resultados similares fueron encontrados por Chitiva y Dussán (2003). En este caso, el proceso de biocatálisis ocurriría en un ambiente restringido por las paredes de las membranas de alginato de sodio en forma de cápsula, mientras que el consorcio bacteriano se encuentra en estado libre en su núcleo líquido. La membrana semipermeable de las cápsulas de alginato de sodio debería permitir la difusión de diferentes sustancias hacia los microorganismos en su interior. Asimismo, eventuales exoenzimas producidas por el consorcio bacteriano podrían difundirse al exterior de las partículas de alginato, por lo que el efecto biodegradador no se limitaría únicamente al área interna de las cápsulas. Dentro de los factores determinantes se encuentra el tamaño del poro en la membrana y el diámetro interno del núcleo (Funami et al. 2009, Martínez et al. 2015). 
En el presente estudio se encontró heterogeneidad en la forma de las cápsulas al usar diferentes concentraciones de alginato de sodio. A concentraciones bajas ( 2 y $2.5 \%$ ), se evidenció la formación de estructuras elipsoidales e irregulares mientras que a concentraciones de 3 y $4 \%$ las cápsulas fueron esféricas y homogéneas. Independientemente de la concentración utilizada, el diámetro de las cápsulas varió de 2 a $3 \mathrm{~mm}$, tamaño similar al reportado por Fleming et al. (2004). Por su parte, la concentración de biomasa inmovilizada presentó diferencias entre las cuatro concentraciones de alginato de sodio estudiadas. Los valores más bajos de inmovilización se presentaron en concentraciones del $4 \%$. La concentración de alginato de sodio al $3 \%$ inmovilizó la mayor cantidad de biomasa $\left(8.1 \times 10^{7} \mathrm{UFC} / \mathrm{g}\right.$ de cápsulas). Esta concentración de alginato de sodio coincide con los resultados reportados por Tao et al. (2009). El mismo estudio concluyó que a esta concentración, características como el rendimiento de transferencia de masa y la estabilidad mecánica también mejoran. Sin embargo, Callone et al. (2008) menciona que, en comparación con otras matrices, el alginato presenta la desventaja de tener baja resistencia mecánica y escasa durabilidad química, lo cual puede dar lugar a fugas de células.

El análisis elemental obtenido al examinar las biopeliculas evidencia los típicos componentes celulares procariotas, en este caso presumiblemente con presencia de exopolímeros bacterianos. No obstante, el presente trabajo sólo supone la presencia de dichos exopolímeros, pero dado su alcance no se determinó la clase o la cantidad de éstos. En el análisis general de la biopelicula (Fig. 5) el carbono representa cerca del $50 \%$ del peso seco, el oxígeno $32 \%$, el nitrógeno $14 \%$, el fósforo $3 \%$ y el azufre $1 \%$; otros elementos traza, entre los que se encuentran hierro, potasio, magnesio, manganeso, cobalto, molibdeno, cobre y zinc se encontraron en porcentajes similares a los reportados en otros análisis (Madigan et al. 1999). No obstante, las preparaciones de microscopia electrónica (Fig. 4) permiten observar las células y estructuras de adhesión, presumiblemente de tipo polimérico. Teniendo en cuenta lo anterior, es probable que el consorcio de bacterias conformado en el presente estudio posea la capacidad de producir exopolímeros. Este tipo de sustancias complementa otras estrategias de adhesión de los microorganismos, como los pili y las fimbrias. Se ha reportado que, en conjunto, estos mecanismos favorecen la adherencia entre células, así como entre células y superficies inertes (Pérez et al. 2008). Las células adheridas como parte de las biopelículas tendrían mayores posibilidades de supervivencia y adaptabilidad, especialmente en condiciones de estrés (Dasgupta et al. 2013, Wang et al. 2015).

Las espumas de poliuretano son materiales porosos que permiten la inmovilización de microorganismos por adhesión (Chitiva y Dussán 2003, Usha et al. 2010). El consorcio bacteriano en estudio se adhirió a dichas matrices, formando una biopelícula en la superficie similar a la reportada por Chitiva y Dussán (2003) y Usha et al. (2010). El análisis estadístico demostró que existen diferencias significativas en la cantidad de biomasa inmovilizada en la mayoría de las matrices de poliuretano analizadas. La excepción son las matrices PUS\#0, PUS\#15, PUS + VIDRIO y PUF\#21, que presentaron los valores más bajos de inmovilización de biomasa y no evidenciaron diferencias significativas entre sí en cuanto a cantidad de biomasa inmovilizada.

Por otra parte, las matrices PUF\#37 y PUF\#10 inmovilizaron la mayor cantidad de biomasa, posiblemente por la extensa área superficial que ofrece su carácter poroso. La alta biodegradabilidad de la PUF\#10 la hace un candidato ideal para usarse en procesos de biodegradación de crudos. Esta matriz podría ser particularmente útil en sistemas industriales, donde la adición de compuestos no biodegradables se encuentra restringida. Por su parte, la PUF\#37 de origen petroquímico no es biodegradable y presenta desventajas en términos de toxicidad, maleabilidad y economía en comparación con la PUF\#10. Estas condiciones hacen de la PUF\#10 un tipo de espuma favorable para el desarrollo de biabsorbentes, la cual puede utilizarse con el doble propósito tanto de inmovilizar microorganismos como de bioabsorber el compuesto a biorremediar (Fernández et al. 2009, Prabhavathi et al. 2014).

Diversos estudios han mostrado la eficiencia del polipropileno, el alginato de sodio y muchos otros agentes inmovilizantes (Díaz et al. 2002, Nuñal et al. 2014). Sin embargo, muchos de los trabajos de inmovilización relacionados con hidrocarburos se enfocan directamente a un solo método de inmovilización o una cepa particular. La utilización de consorcios bacterianos plantea retos significativos desde el punto de vista operacional. Este trabajo es una de las pocas referencias con relación al análisis de consorcios bacterianos conformados por múltiples géneros, en una amplia variedad de matrices de inmovilización (Bayat et al. 2015).

Los resultados de nuestro estudio sugieren que para obtener el mejor rendimiento de la actividad bacteriana durante los procesos asociados a la inmovilización, es necesario tener en cuenta que no 
todos los compuestos y concentraciones funcionan de la misma manera sobre las diferentes cepas. Esto último es particularmente importante cuando se utilizan consorcios de cepas nativas asociadas a sitios contaminados.

En el presente trabajo se evaluaron no sólo diferentes concentraciones de alginato de sodio para la inmovilización de consorcios bacterianos incluyendo bacterias nativas, sino que además se comparó la inmovilización del consorcio en matrices de poliuretano, variando su composición química y estructural. La evidencia sugiere que los diferentes agentes inmovilizadores son efectivos en diferentes proporciones. Es muy probable que el tipo y fisiología de los diferentes tipos de bacterias utilizados influencien directa o indirectamente la adherencia de éstas a los diferentes tipos de matrices.

\section{CONCLUSIONES}

El consorcio bacteriano fue conformado por cinco cepas bacterianas aerobias pertenecientes a los géneros Bacillus sp., Pseudomonas sp., Serratia sp., Enterobacter sp. y Raoultella sp. Se consideró el consorcio como potencialmente degradador de hidrocarburos, ya que todas las cepas formaron estructuras micelares y en conjunto redujeron la concentración de los HTP en un $33 \%$ en el medio de cultivo con hidrocarburos como única fuente de carbono.

Los ensayos de inmovilización del consorcio se llevaron a cabo mediante la evaluación de una variedad de matrices naturales (alginato de sodio) y sintéticas (poliuretano). Se determinó que la concentración óptima para la inmovilización de este consorcio en particular usando alginato de sodio fue del $3 \%$. Ésta favoreció la formación de cápsulas con bordes regulares y la inmovilización de la mayor cantidad de unidades formadoras de colonia por gramo de cápsula.

El análisis estadístico demostró que existen diferencias significativas entre la biomasa inmovilizada en la mayor parte de las matrices de poliuretano analizadas. De estas últimas destacaron PUF\#37 y PUF\#10, con mejor rendimiento en la adhesión de los microorganismos. No obstante, la PUF\#10 es en principio más atractiva para tratamientos de biorremediación por su carácter biodegradable. Este trabajo destaca la necesidad de realizar análisis de inmovilización previos a procesos de bioremediación, particularmente cuando se trata de microorganismos nativos. Con base en nuestros su comparación con los reportados en la literatura, se evidencia que la eficiencia para la inmovilización celular de diferentes cepas en matrices es probablemente un proceso altamente dependiente de las especies a inmovilizar.

\section{AGRADECIMIENTOS}

Está investigación fue financiada por Colciencias a través de la convocatoria 642-2013 Locomotora de la innovación para el apoyo del desarrollo tecnológico. Asimismo, los investigadores agradecen al ingeniero Reinaldo Villalba por proporcionar las matrices de inmovilización sintética y al economista Ronald Rueda por su enorme colaboración durante la ejecución del proyecto.

\section{REFERENCIAS}

Ahuja A. y Souza S.F. (2009). Bioprocess for solubilization of rock phosphate on starch based medium by Paecilomyces masquandii immobilized on polyurethane foam. Appl. Biochem. Biotech. 152, 1-5. DOI: $10.1007 / \mathrm{s} 12010-008-8221-4$

APHA/AWWA/WEF (2012). Standard methods for examination of water and wastewater, 22nd ed. Washington, American Public Health Association/American Water Works Association/Water Environment Federation [en línea]. http://www.standardmethods.org 03/02/2016

Arrieta O. M. (2011). Evaluación de la influencia del bioestímulo sobre un suelo contaminado con diésel y su integración a la gestión ambiental. Tesis de Maestría. Facultad de Minas, Escuela de Geociencias y Medio Ambiente, Universidad Nacional de Colombia, Medellín, Colombia, 123 pp.

Barrios Y. (2011). Bioremediation: A tool for the management of oil pollution in marine ecosystems. Biotecnol. Apl. 28 (2), 69-76.

Bayat Z., Hassanshahian M. y Cappello S. (2015). Immobilization of microbes for bioremediation of crude oil polluted environments: A mini review. Open Microbiol. J. 9, 48-54.

DOI: $10.2174 / 1874285801509010048$

Bonfield J.K. y Whitwham A. (2010). Gap5-editing the billion fragment sequence assembly. Bioinformatics 26 (14), 1699-1703. DOI: 10.1093/bioinformatics/btq268

Brune K.D. y Bayer T.S. (2012). Engineering microbial consortia to enhance biomining and bioremediation. Front. Microbiol. 3 (203). DOI: $10.3389 /$ fmicb.2012.00203

Callone E., Campostrini R., Carturan G., Cavazza A. y Guzzon R. (2008). Immobilization of yeast and bacteria cells in alginate microbeads coated with silica 
membranes: Procedures, physicochemical features and bioactivity. J. Mater. Chem. 18 (40), 4839-4848. DOI: $10.1039 / \mathrm{b} 807301 \mathrm{e}$

Chitiva L. y Dussán J. (2003). Evaluación de matrices para la inmovilización de Pseudomonas spp. en biorremediación de fenol. Rev. Colomb. Biotecnol. V (2), 5-10.

Dasgupta D., Ghosh R. y Sengupta T.K. (2013) Biofilmmediated enhanced crude oil degradation by newly isolated Pseudomonas species. ISRN Biotechnol. 2013, 250749. DOI: 10.5402/2013/250749

Díaz M.P., Boyd K.G., Grigson S.J. y Burgess J.G. (2002). Biodegradation of crude oil across a wide range of salinities by an extremely halotolerant bacterial consortium MPD-M, immobilized onto polypropylene fibers. Biotech. Bioeng. 79 (2), 145-53.

DOI: 10.1002/bit.10318

Echeverri G.E., Manjarrez G., y Cabrera M. (2010). Aislamiento de bacterias potencialmente degradadoras de petróleo en hábitats de ecosistemas costeros en la Bahía de Cartagena, Colombia. Nova 8 (13), 76-86.

Emtiazi G., Shakarami H., Nahvi I. y Mirdamadian S.H. (2005). Utilization of petroleum hydrocarbons by Pseudomonas sp. and transformed Escherichia coli. Afr. J. Biotechnol. 4 (2), 172-176.

Fernández J.A., Henao L.M., Pedroza A.M. y Quevedo B. (2009). Inmovilización de hongos ligninolíticos para la remoción del colorante negro reactivo 5. Rev. Colomb. Biotecnol. XI (1), 59-72.

Ferreira T.C., Santos F.J. y Pessoa F. (2013). Biorremediación de un suelo tropical contaminado con residuos aceitosos intemperizados. Rev. Int. Contam. Ambie. 29 (1), 21-28.

Fleming D.L., Linares K.A., Ikuma K., Love N.G., Meehan K. y Love B.J. (2004). Evaluating immobilization matrices for capturing P. aeruginosa. En: Evaluating bacterial cell immobilization matrices for use in a biosensor. Tesis de maestría. Virginia Polytechnic Institute and State University, Blacksburg, Virginia, EUA, 23-37.

Funami T., Fang Y., Noda S., Ishihara S., Nakauma M., Draget K.I., Nishinari K. y Phillips G.O. (2009). Rheological properties of sodium alginate in an aqueous system during gelation in relation to supermolecular structures and $\mathrm{Ca}^{2+}$ binding. Food Hydrocolloid. 23, 1746-1756.

DOI: 10.1016/j.foodhyd.2009.02.014

Garzón C. y Barragán B.E. (2008). Inmovilización microbiana: tecnicas y usos en el tratamiento de residuos tóxicos. Rev. Sistem. Ambi. 2 (1), 23-24.

Gómez S., Amaya D., Maldonado C., Martínez M.M., Quevedo B., Soto A.B. y Pedroza A.M. (2008). Evaluación de tres hongos lignolíticos y de Aspergillus niger como alternativa para el tratamiento de aguas residuales del curtido de pieles. Rev. Int. Contam. Ambie. 24 (3), 93-106.

Hincapié G. y Ramírez M. (2009). Evaluación de la biodegradación aerobia de poliuretano residual generado en la industria de fabricación de refrigeradores. Rev. Invest. Apli. 5, 15-25.

Hoskeri R.S., Mulla S.I. y Ninnekar H.Z. (2014). Biodegradation of chloroaromatic pollutants by bacterial consortium immobilized in polyurethane foam and other matrices. Biocatal. Agric. Biotechnol.3 (4), 390-396.

DOI: 10.1016/j.bcab.2014.03.001

Lakshmi P.J. (2013). Biodegradation of diesel by Aeromonas hydrophila. Int. J. Pharm. Sci. Invent. 2 (4), 24-36.

Łebkowska M., Zborowska E., Karwowska E., Miaskiewicz E., Muszynski A., Tabernacka A., Naumczyk J. y Jeczalik M. (2011). Bioremediation of soil polluted with fuels by sequential multiple injection of native microorganisms: Field-scale processes in Poland. Ecol. Eng. 37, 1895-1900.

DOI: 10.1016/j.ecoleng.2011.06.047

López J.B., Quintero J., Guevara A.L., Jaimes D.C., Gutiérrez S.M. y Miranda J. (2006). Biorremediación de suelos contaminados con hidrocarburos derivados del petróleo. Nova 4 (5), 82-90.

Lozano N.P. (2005). Biorremediación de ambientes contaminados con petróleo. Tecno. Gest. 11 (1), 51-55.

Madigan M.T., Martinko J.M. y Parker J. (1999). Crecimiento microbiano. En: Brock. Biología de los microorganismos, $8^{\text {a }}$ ed. (I. Capella, Ed.). Prentice Hall Iberia, Madrid, España, pp. 149-177.

Malik Z. y Ahmed S. (2012). Degradation of petroleum hydrocarbons by oil field isolated bacterial consortium. Afr. J. Biotechnol. 11 (3), 650-658.

DOI: $10.5897 / A J B 11.036$

Manohar S. y Karegoudar T.B. (1998). Degradation of naphthalene by cells of Pseudomonas sp. strain NGK 1 immobilized in alginate, agar and polyacrylamide. Appl. Microbiol. Biotechonol. 49, 785-792.

DOI: $10.1007 / \mathrm{s} 002530051247$

Martínez A., Pérez M.E., Pinto J., Gurrola B.A. y Osorio A.L. (2011). Biorremediación de suelo contaminado con hidrocarburos empleando lodos residuales como fuente alterna de nutrientes. Rev. Int. Contam. Ambie. 27 (3), 241-252.

Martínez C., Pereira S., Tiemi M., Bona E., Portilho M. y Matioli G. (2015). Effective immobilization of Agrobacterium sp. IFO 13140 cells in loofa sponge for curdlan biosynthesis. Molecules 20, 7957-7973. DOI: $10.3390 /$ molecules20057957

Monge O., Valenzuela J.L., Acedo E., Certucha M.T. y Almendáriz F.J. (2008). Biosorción de cobre en sistema 
por lote y continuo con bacterias aerobias inmovilizadas en zeolita natural (clinoptilolita). Rev. Int. Contam. Ambie. 24 (3), 107-115.

Moreno N. y Ospina X.A. (2008). Evaluación de inductores metálicos y co-sustratos para la remoción de negro reactivo 5 empleando Proteus ostreatus inmovilizado en fique. Tesis de Pregrado. Facultad de Ciencias, Pontificia Universidad Javeriana, Bogotá, Colombia, 137 pp.

Moslemy P., Neufeld, R.J. y Guiot, S.R. (2002). Biodegradation of gasoline by gellan gum-encapsulated bacterial cells. Biotechnol. Bioeng. 80 (2), 175-184. DOI: $10.1002 /$ bit.10358

Mrozik A. y Piotrowska Z. (2010). Bioaugmentation as a strategy for cleaning of soils contaminated with aromatic compounds. Microbiol. Res. 165, 363-375. DOI: 10.1016/j.micres.2009.08.001

Nuñal S.N., Santander-de León S.M., Bacolod E., Koyama J. Uno S., Hidaka M., Yoshikawa T. y Maeda H. (2014). Bioremediation of heavy oil-polluted seawater by a bacterial consortium immobilized in cocopeat and rice hull powder. Biocontrol Sci. 19 (1), 11-22.

Núñez R.R., Lorenzo, M., Ortiz, E. y Oramas J. (2010). Biorremediación de la contaminación de petróleo en el mar. Rev. Electró. Agen. Medio Amb.10 (19), 1-6.

Olguín E.J., Hernández M.E. y Sánchez G. (2007). Contaminación de manglares por hidrocarburos y estrategias de biorremediación, fitorremediación y restauración. Rev. Int. Contam. Ambie. 23 (3), 139-154.

Pérez R.M., Camacho M.I., Gómez J.M., Ábalos A., Viñas M. y Cantero D. (2008). Aislamiento y selección de una cepa bacteriana degradadora de hidrocarburos a partir de suelos contaminados con petróleo. Rev. CENIC. Cienc. Biol. 39 (1), 44-51.

Prabhavathi P., Rajendran R., Karthiksundaram S., Pattabi S., Dinesh S. y Santhanam P. (2014). Enhanced bioremediation efficiency of denim industrial effluent using bacterial biofilm onto polyurethane matrix. Appl. Biochem. Microbiol. 50 (6), 554-562. DOI: $10.1134 / \mathrm{S} 0003683814060131$

Quast C., Pruesse E., Yilmaz P., Gerken J., Schweer T., Yarza P., Peplies J. y Glöckner F. (2013). The SILVA ribosomal RNA gene database project: improved data processing and web-based tools. Nucl. Acids Res. 41(D1), D590-D596. DOI: 10.1093/nar/gks1219

Quek E., Ting Y.P. y Tan H. (2006). Rhodococcus sp. F92 immobilized on polyurethane foam shows ability to degrade various petroleum products. Bioresour. Technol. 97, 32-8.

DOI: 10.1016/j.biortech.2005.02.031

Rahman R.N., Ghaza F.M., Salleh A.B. y Basri M. (2006). Biodegradation of hydrocarbon contamination by immobilized bacterial cells. J. Microbiol. 44 (3), 354-359
Riojas H.H., Torres L.G., Moncada I., Balderas J. y Gortáres P. (2010). Efectos de los surfactantes en la biorremediación de suelos contaminados con hidrocarburos. Rev. Qui. Viva. 9 (3), 120-145.

Rosselló R. y Amann R. (2001). The species concept for prokaryotes. FEMS Microbiol. Mol. Biol. Rev. 25 (1), 39-67.

Shankar S., Kansrajh C., Dinesh M.G., Satyan R., Kiruthika S. y Tharanipriya A. (2014). Application of indigenous microbial consortia in bioremediation of oil-contaminated soils. Int. J. Environ. Sci. Technol. 11 (2), 367-376. DOI: 10.1007/s13762-013-0366-1

Silveira S.C., Miranda C., Guedes L.M. y Tédde S. (2013). Immobilization of microbial cells: A promising tool for treatment of toxic pollutants in industrial wastewater. Afr. J. Biotechnol. 12 (28), 4412-4418.

DOI: $10.5897 / \mathrm{AJB} 12.2677$

Sossa D., Navarro M.A., Matiz A., Mercado M., Quevedo B. y Pedroza A.M. (2008). Inmovilización de Bacillus licheniformis y Saccharomyces cerevisiae para la producción de etanol a partir de almidón de papa. Univ. Sci. 13 (2), 149-161.

Sultana K., Godward G., Reynolds N., Arumugaswamy R., Peiris P. y Kailasapathy K. (2000). Encapsulation of probiotic bacteria with alginate-starch and evaluation of survival in simulated gastrointestinal conditions and in yoghurt. Int. J. Food Microbiol. 62 (1-2), 47-55. DOI: 10.1016/S0168-1605(00)00380-9

Tao X.Q., Lu G.N., Liu J.P., Li T. y Yang L. (2009). Rapid degradation of phenanthrene by using Sphingomonas sp. GY2B immobilized in calcium alginate gel beads. Int. J. Environ. Res. Public Health 6 (9), 2470-2480. DOI: 10.3390/ijerph6092470

Usha M.S., Sanjay M.K., Gaddad S.M. y Shivannavar C.T. (2010). Degradation of h-acid by free and immobilized cells of Alcaligenes latus. Braz. J. Microbiol. 41 (4), 931-945. DOI: 10.1590/S1517-83822010000400012

Vargas P.A., Cuéllar R.R. y Dussán J. (2004). Biorremediación de residuos del petróleo. Hipótesis, Apuntes Científicos Uniandinos 4, 42-49

Vennila R. y Kannan V. (2011). Bioremediation of petroleum refinery effluent by Planococcus halophilus. Afr. J. Biotechnol. 10 (44), 8829-8833.

DOI: $10.5897 / A J B 10.597$

Verbelen P.J., Shutter D.P., Delvaux F., Verstrepen K.J. y Delvaux F.R. (2006). Immobilized yeast cell systems for continuous fermentation applications. Biotechnol. Lett. 28 (19), 1515-1525.

DOI: $10.1007 / \mathrm{s} 10529-006-9132-5$

Wang N., Adams G., Buttery L., Falcone F.H. y Stolnik S. (2009). Alginate encapsulation technology supports embryonic stem cells differentiation into insulinproducing cells. J. Biotechnol. 144 (4), 304-312.

DOI: $10.1016 /$ j.jbiotec.2009.08.008 
Wang J., Lu H., Zhou Y, Song Y., Liu G. y Feng Y. (2013). Enhanced biotransformation of nitrobenzene by the synergies of Shewanella species and mediatorfunctionalized polyurethane foam. J. Hazard. Mater. 252-253, 227-232.

DOI: 10.1016/j.jhazmat.2013.02.040

Wang X., Wang X., Liu M., Bu Y., Zhang J., Chen J. y Zhao J. (2015). Adsorption-synergic biodegradation of diesel oil in synthetic seawater by acclimated strains immobilized on multifunctional materials. Mar. Pollut. Bull. 92 (1-2), 195-200.

DOI: 10.1016/j.marpolbul.2014.12.033
Xu Y. y Lu M. (2010). Bioremediation of crude oil-contaminated soil: comparison of different biostimulation and bioaugmentation treatments. J. Hazard. Mater. 183 (1-3), 395-401. DOI: 10.1016/j.jhazmat.2010.07.038

Yamaguchi T., Ishida M. y Suzuki T. (1999). An immobilized cell system in polyurethane foam for the lipophilic micro-alga Prototheca zopfii. Process Biochem. 34 (2), 167-171. DOI: 10.1016/S0032-9592(98)00084-3 Young C.C., Rekha P.D., Lai W.A. y Arun A.B. (2006). Encapsulation of plant growth-promoting bacteria in alginate beads enriched with humic acid. Biotechnol. Bioeng. 95 (1), 76-83. DOI: 10.1002/bit.20957 